\title{
An Android based System for Locating Nearest National Health Insurance Scheme Hospital to Patient Location
}

\author{
O.A. Daramola \\ Department of Information \\ Technology, Federal University of \\ Technology, Akure
}

\author{
T.I. Famutimi \\ Department of Computer Science \& \\ Information Tech., Bowen \\ University Iwo, Nigeria
}

\author{
A.E. Akinwonmi \\ Department of Computer Science, \\ Federal University of Technology, \\ Akure
}

\begin{abstract}
Universal Health Insurance will give countries especially the developing ones the opportunity to make healthcare available to everyone irrespective of status. This will enable everyone share the financial burden of having access to medical services. The use of mobile technology in accessing healthcare offers a great opportunity in developing countries where healthcare is out of reach of common man and inadequate. This research takes advantage of the benefits of mobile technology in addressing the limitations of the National Health Insurance Scheme. Currently in Nigeria, any individual registered under the scheme is restricted to his/her primary healthcare clinic and when need be, a referral can be done from the primary healthcare clinic. The system is proposing locating and making available an NHIS hospital to enrollee anytime anywhere an enrollee is in need of healthcare. The system allows enrollees to gain access to healthcare services in any accredited NHIS hospital nearest to them at the time health services are required. The system consists of a two-tier client-server configuration. The client side, (an android device) is the enrollees' module and hospital module, while the server side consists of a NHIS centralized database hosted on a web server. The system was implemented using Hypertext Preprocessor (PHP), JavaScript (JS), Hypertext Markup Language (HTML) and Cascading Style Sheets (CSS) as the front-end. My Structured Query Language (My SQL) database was used as the back-end.
\end{abstract}

\section{General Terms}

NHIS, Health Insurance, Nearest Hospital, Health Information System.

\section{Keywords}

Mobile Health, Health Insurance, Information System, National Health Insurance Scheme.

\section{INTRODUCTION}

The world needs a healthy population to achieve socioeconomic and sustainable development goals [2]. One of the new technologies that is making a huge impact on healthcare is mobile health (mHealth) systems. The mode of interaction and communication between people and organizations has been greatly influenced by the recent growth of mobile technologies and social networks.

In developing countries, people with low income do not usually have access to enough and adequate healthcare; this is because many cannot afford it. Therefore, the World Health Organization (WHO) [11] advocates that developing countries organize Universal Health Insurance (UHI) so that the financial burden of medical services can be shared by everyone thereby given everyone opportunity to access healthcare services at minimum cost affordable to all.
In order for all citizens to get easy access to healthcare, the Nigerian government put in place a National Health Insurance scheme (NHIS).

In Nigeria currently, the NHIS system has not been fully computerized. The system is such that that a patient which has registered under the NHIS can only have access to healthcare with his or her primary healthcare provider. When a referral is needed, a note is given to the enrollees and the hospital where the enrollees are being referred to is being contacted. National Health Insurance Scheme (NHIS) is static in location as patient information is not mobile.

In this work, we propose a system that will assist an NHIS enrollee in having access to healthcare irrespective of his or her primary healthcare and location when healthcare is needed.

\subsection{Mobile Technology in Health Care Delivery}

According to World Health Organization [11] mobile devices are now available to more people than power grids, road system, water works or fiber optic networks in many developing countries. It is now easier for the public and private sectors to reach communities especially the rural ones through the use of mobile services.

Many developing countries with large populations find it difficult to achieve Universal Health Coverage (UHC), and as such individuals have to be responsible for the payment of medical services whenever they need such [7]. The Global Observatory for eHealth of WHO [10] defines mHealth as medical and public health practice that is achieved by the use of mobile technologies. One major advantage of mHealth is that healthcare can be given anytime anywhere without hindrance because patient records can be made available without stress [4].

Mobile health generally involves the use of mobile technologies for health care delivery.

\subsection{Health Care Delivery Index of Development}

The health sector can be considered as one of the primary engines of growth and development in any country. Whatever progress the Nigerian health sector has witnessed has not been visible to the world because of the various challenges that the health sector has been facing from time to time [6]. One major challenge in Nigeria is that people's access to healthcare services is limited because many cannot afford it [2]. In today's healthcare systems, affordability and successful health care operations have to eliminate all waste and inefficiency from its delivery systems. Thus, health is a major need of the people for wealth creation, and which will in turn 
bring about national development [8]. Therefore, government at all levels in any country should be responsible for healthcare provision for her citizens.

However, private providers of health care have a visible role to play in health care delivery in a nation like Nigeria that operates a mixed economy, [3].

\subsection{National Health Insurance Scheme (NHIS)}

Health care financing has to do with ways by which resources for basic public health programs are generated and managed for health service delivery system [8]. Every tier of government must see health care delivery as her responsibility to the citizens and thus a means of providing quality health care services is needed.

Health insurance is an insurance coverage that pays for medical expenses incurred by the insured without any strain on the finances of the insured. Many citizens cannot afford the needed medical expenses; hence many suffer untold hardship. The aim of Health Insurance is to protect citizens against high medical costs while making sure they have access to good and affordable healthcare services, According to NHIS operational guidelines (2012), there are two types of health insurance: National or Social Health Insurance Scheme and Voluntary or Private Health Insurance Scheme.

\subsubsection{National or Social Health Insurance Scheme.}

A social health insurance scheme must see health of individuals as assets to the society. Such schemes are managed by government agencies, and or a non-for-profit institution. Premiums are paid by participants or on their behalf in order to fund the scheme. It is usually for a defined population, like a nation. Participation in such schemes is made compulsory or the government/organization can subsidized so that most eligible individuals will choose to subscribe. The level of contribution is determined by ability to pay such as percentage of an individual income and not by health risk and it is non-profit based. The benefits, eligibility requirements and other aspects of this type of scheme are defined by statue. Social Insurance schemes place a great importance on the adequacy of the social benefits for all participants.

\subsubsection{Voluntary or Private Health Insurance Scheme:}

Participating in this insurance is often voluntary and anyone participating must purchase the insurance, while a participant has the opportunity to choose his/her insurer. In this scheme, the risks, both financial and health are taken care of by the enrollee, the scheme is organized and administered by an insurance company or other private agency, with the provisions specified in a contract. The programs is designed with emphasis on equity between individual enrollees of coverage. The insurer does not have a unilateral right to change or terminate coverage before the end of the contract (except in cases as non-payment of premiums).

\section{REVIEW OF RELATED WORKS}

[9] presented "an integrated health management system for national health insurance scheme in Nigeria". The authors considered that the paper-based processes being adopted by the NHIS in registering patients is slow and it takes about 90days for an enrollee to be fully registered before the insurance scheme can be accessed. The author developed an Integrated NHIS system where transactions pertaining to different operations of the organization can be carried out. The system was tested by 80 members of the stakeholders using five parameters; utility, accuracy, timeliness, userfriendliness and responsiveness and it was adjudged to be good. The system only addressed the delay in registration by reducing the turn-around time of enrollees' access to quality health care with the NHIS. Also, duplication and misrepresentation of data were eradicated. Another limitation of the system is that it does not support mobility. Mobility is a major factor that should be considered in a system in this era of ubiquitous computing.

[12] presented "a web based National Health Insurance Scheme (NHIS) Outpatient Medical Appointment Booking System where patients can access available personnel or doctor schedule in order to book an appointment with the corresponding time as specified by the doctor. The authors observed that lots of patients missed appointments with their healthcare providers in Nigeria and this is a great cause for concern. Hence, an integrated healthcare system was proposed to provide seamless access to patients. The objective was to develop a web based NHIS outpatient medical appointment booking system. The system also afforded healthcare workers easy access to manage patients' appointments and to generate relevant and adequate reports. The system was not design to diagnose or prescribe drugs for usage, it only focused on booking of appointments.

[1] presented "A framework of a web-based database system for National Health Insurance Scheme". The author observed that in Nigeria, patients data managed by NHIS was scattered and there is no central patient management information system for the health care centers to access patient information for healthcare delivery., hence a system that will properly organize the data for easy accessibility and retrieval was presented. A framework of a web-based database system for management of patients' information was proposed. The system design used a three-tier web model architecture. Apache server, PHP, HTML and MySQL. The system enhanced the activities of NHIS in patient's information management through the web-based database system. However, the system is mobile; it is only designed for enrolling and storing patients' records.

\section{Architecture of The System}

Below is the architecture of the system in fig1.

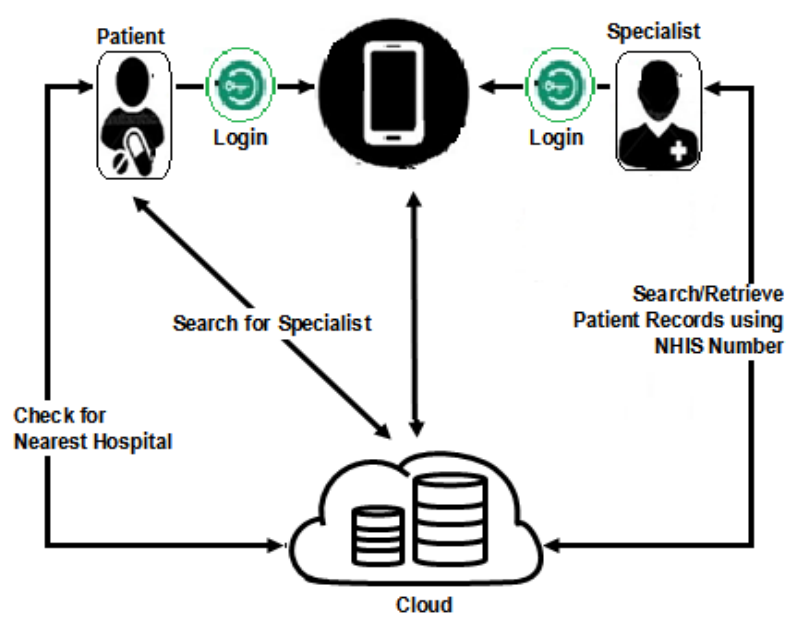

Fig 1: Architecture of the system 
The first module contains a login page for the registered NHIS patient. The patient will have to input his/her username and password. If the patient is a new patient, he/she will have to register in order to proceed. After logging in, the patient selects medical specialist to see the different kinds of specialist listed and check for a specialist he/she needs. After clicking on the needed specialist, a list of hospitals with the specialist is listed with the location. To get the location of the hospital closer to patient, the patient will have to turn on the location icon on the mobile device.

Hospital: The record unit in the hospital must have registered on the application. After registration, the record unit can now login to search for details of patient using NHIS number.

Central Database: MySQL Database is used for the mobile application with a table structure containing patients, specialists and hospitals. The database can be queried and updated.

Internet: The mobile application user can use mobile internet on his/her android device or an internet can be provided. The mobile application and the Web application are synchronized with the use of Web service where data can be conveyed via GPRS, 3G or WIFI.

The system consists of a two-tier client-server configuration. The client side, (an android device) is the patient module and hospital record unit module, while the server side consists of a centralized database which is hosted on a web server. The patient module allowed authorized access and transactions on patient's mobile device while the record unit module supports records and transactions pertaining to registered patients.

The system adopted the Haversine distance formula to locate nearest NHIS hospital to patient. Let $\varphi_{\mathrm{n}}$ and $\gamma_{\mathrm{n}}$ be the latitude component and longitude component of a geodesic point coordinates. The patient is located at point $\left(\varphi_{\mathrm{P}}, \gamma_{\mathrm{P}}\right)$ while the hospital is located at point $\left(\varphi_{\mathrm{H}}, \gamma_{\mathrm{H}}\right)$ locations respectively. In geodesic term, the pathobject $(\rho)$ between point $\left(\varphi_{\mathrm{P}}, \gamma_{\mathrm{P}}\right)$ and $\operatorname{point}\left(\varphi_{\mathrm{H}}, \gamma_{\mathrm{H}}\right)$ is obtained by using the snapping algorithm (SnapToRoad) as given in equation (1)

$$
\rho \leftarrow \operatorname{SnapToRoad}\left(\operatorname{point}\left(\varphi_{\mathrm{P}}, \gamma_{\mathrm{P}}\right), \operatorname{point}\left(\varphi_{\mathrm{H}}, \gamma_{\mathrm{H}}\right)\right)
$$

$\mathrm{p}$ will be converted to a polyline $\Pi$ by using polyline encoding algorithmn as follows:

\section{$\Pi \leftarrow$ PolyLine.Encode $(\rho)(2)$}

In addition to creating $\Pi$, equation (2) returns the geodesic coordinates of all vertexes (intersections) of all adjacent lines in $\Pi$. Thus, polyline Пwill be composed of $x$ number

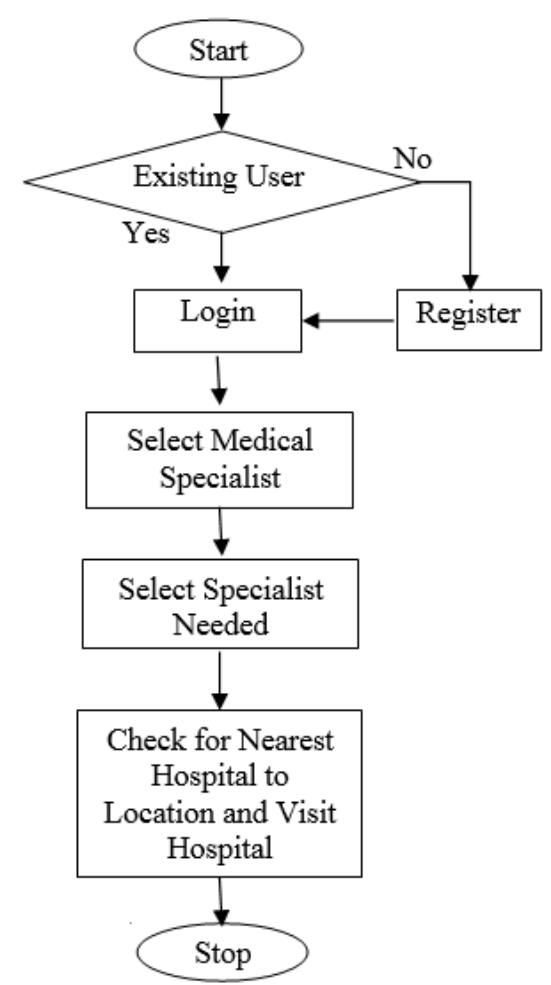

Fig2: Flowchart of the mobile application for Patient.

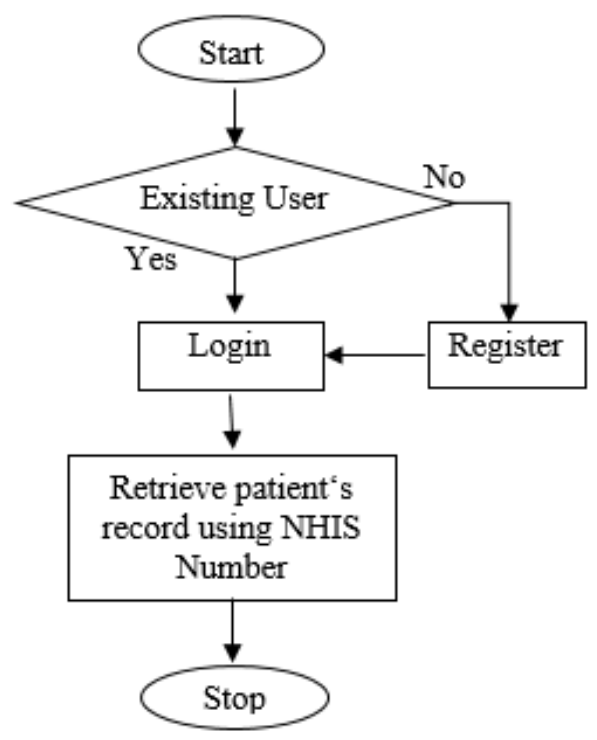

Fig 3: Flowchart of mobile application for hospital record unit

of joined lines $\mathrm{L}_{0}$ to $\mathrm{L}_{\mathrm{x}-1}$ with vertexes at $\mathrm{V}_{1}$ to $\mathrm{V}_{\mathrm{x}-1}$ in points $\mathrm{P}_{1}$ to $\mathrm{P}_{\mathrm{x}-1}$, having coordinates $\left(\varphi_{1}, \gamma_{1}\right)$ to $\left(\varphi_{\mathrm{x}-1}, \gamma_{\mathrm{x}-1}\right)$. Coordinate $\left(\varphi_{\mathrm{P}}, \gamma_{\mathrm{P}}\right)$ implies $\left(\varphi_{0}, \gamma_{0}\right)$ while $\left(\varphi_{\mathrm{x}}, \gamma_{\mathrm{x}}\right)$ implies $\left(\varphi_{\mathrm{H}}, \gamma_{\mathrm{H}}\right)$. Then, equation (3) and (4) are:

$$
\begin{aligned}
& \mathrm{P}\left(\varphi_{\mathrm{P}}, \gamma_{\mathrm{P}}\right) \Rightarrow \mathrm{P}\left(\varphi_{0}, \gamma_{0}\right) \\
& \mathrm{H}\left(\varphi_{\mathrm{H}}, \gamma_{\mathrm{H}}\right) \Rightarrow \mathrm{H}\left(\varphi_{\mathrm{x}}, \gamma_{\mathrm{x}}\right)
\end{aligned}
$$

The geodesic length or distance $(d)$ of any line $\mathrm{L}_{\mathrm{n}} \in\left\{\mathrm{L}_{0}\right.$ to $\mathrm{L}_{\mathrm{x}}$ ${ }_{1}$ \} a subset of polyline $\Pi$ is computed using the Haversine distance formula in equation (5). 


$$
d_{n}=2 r \operatorname{Sin}^{-1}(G)
$$

Where Gis

$\left(\sqrt{\operatorname{Sin}^{2}\left(\frac{\varphi_{n+1}-\varphi_{n}}{2}\right)+\cos \left(\varphi_{n}\right) \cos \left(\varphi_{n+1}\right) * \operatorname{Sin}^{2}\left(\frac{\gamma_{n}-\gamma_{n+1}}{2}\right)}\right)$

$r$ is the earth radius. The distance (D) between patient at

$\left(\varphi_{\mathrm{P}}, \gamma_{\mathrm{P}}\right)$ and Hospital at $\left(\varphi_{\mathrm{H}}, \gamma_{\mathrm{H}}\right)$ estimated as follows:
Since D is the sum of the lengths of the subset lines in the polyline object. Taking equation (3) into cognizance

$$
D=\sum_{n=0}^{x-1} d_{n}
$$

On substituting (5) into, (6) we have:

$$
D=\sum_{n=0}^{x-1} 2 r \operatorname{Sin}^{-1}(G)
$$

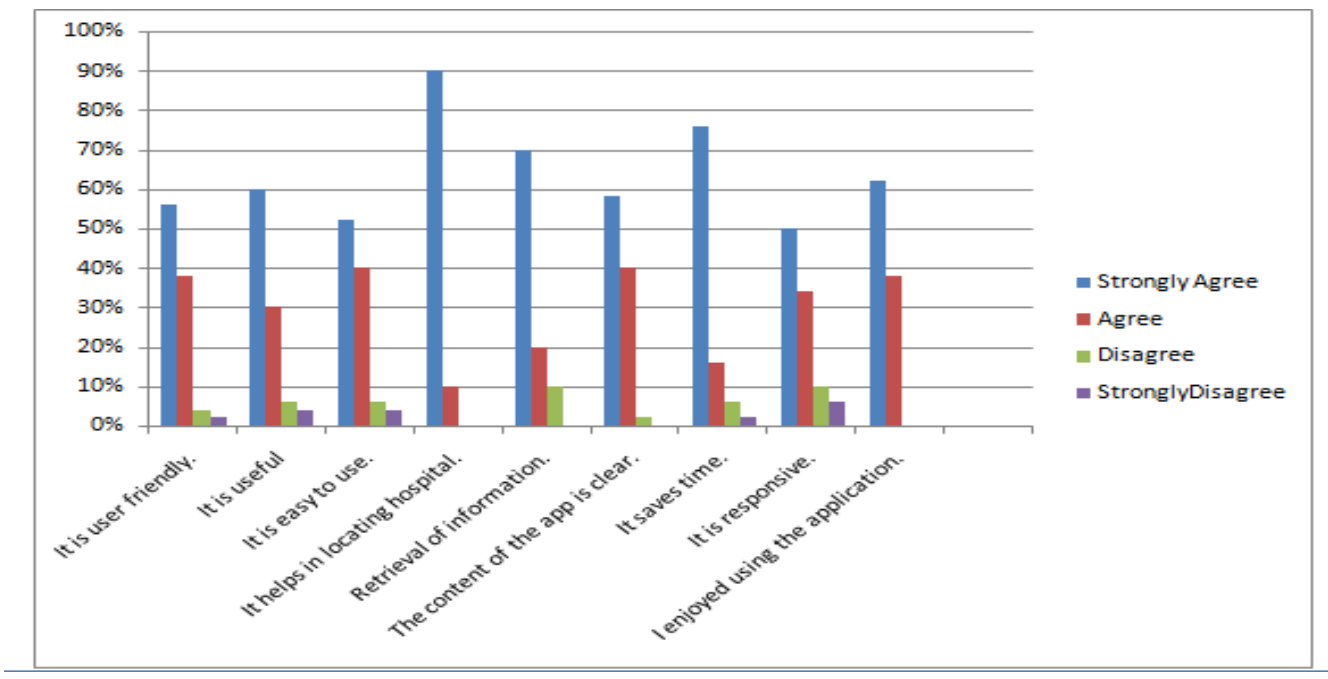

Fig 4: Graph showing performance of the system

The mobile application was implemented using the following tools: Hypertext Preprocessor (PHP), Hypertext Markup Language (HTML), JavaScript (JS) and Cascading Style Sheets (CSS) as the front-end which will allow patients to check for a medical specialist and get the list of nearby hospitals with the specialist. The hospital record unit too allows patients details to be checked using NHIS number. My Structured Query Language (My SQL) database was used as the back-end to store and retrieve information.

\section{RESULT}

In order to evaluate the usability and performance of the application, it was tested on mobile device of selected enrollees and medical record officer. Questionnaire method of data collection was used. The questionnaire was given to patients and record officers after using the mobile application, the questionnaires allow correspondent with choices of options (Agree, Strongly Agree, Disagree, Strongly Disagree). The questionnaire was completed by 25 enrollees and 25 medical record officers making a total of 50 users, which includes 31 females and 19 males. The result of the evaluation showed and highlighted the usefulness and functionality of the mobile

application. The questions include: if it is user friendly; if it is easy to use; if it helps in locating hospital; if it is useful; if it is responsive; if it saves time; if it retrieves information; if the content is clear and if the user enjoy using the application.

$56 \%$ of users "Strongly Agree" that the application is user friendly, 38\% "Agree" that the application is helpful while 4\% "Disagree" and 2\% "Strongly Disagree".

$60 \%$ of users "Strongly Agree" that the application is useful. $30 \%$ "Agree" that it is useful, while 6\% "Disagree" and 4\% "Strongly Disagree".
$52 \%$ of users "Strongly Agree" that the application is easy to use. $40 \%$ "Agree" that it is easy to use, while 6\% "Disagree" and $2 \%$ "Strongly Disagree".

$90 \%$ of users "Strongly Agree" that the application saves time in locating hospital .10\% "Agree" that it saves time in locating hospital, while none "Disagree" and none "Strongly Disagree". Thus, this shows that the application was really helpful in locating hospitals.

$70 \%$ of users "Strongly Agree" that the application helps in retrieval of information $.20 \%$ "Agree" it helps in retrieving of information, while 10\% "Disagree" due to poor network failure, and none "Strongly Disagree". Thus, this shows that users find the easy to retrieve information.

$58 \%$ of users "Strongly Agree" that the content of the application is clear. $40 \%$ "Agree" the application content is also clear, while 2\% "Disagree" that it is clear, and none "Strongly Disagree".

$76 \%$ of users "strongly Agree" that the application saves time. $16 \%$ "Agree" the application saves time, 6\% "Disagree" it saves time due to poor network and 2\% "Strongly Disagree" due to poor network also.

$50 \%$ of users "Strongly Agree" that the application is responsive. 34\% "Agree" the application is responsive, $10 \%$ "Disagree" the application is responsive and 6\% "Strongly Disagree" the application is responsive.

$62 \%$ of users "Strongly Agree" that they enjoy using the application. 38\%" Agree" they enjoy using the application, none "Disagree", and none "Strongly Disagree". Thus, this shows the users enjoyed using the application. 


\section{CONCLUSION}

Mobile application has gradually been in use in the health industry and it is expanding. The mobile application helps patients to easily locate a specialist and their hospital location in this modern era of telecommuting.

\section{CONTRIBUTION TO KNOWLEDGE}

This research has presented an application which canavail an NHIS patientwith the information about the nearest available hospital location and available specialists, while being supported by a centralized database system.

\section{REFERENCES}

[1] Akwukwuma V. N. and Igodan C. E. (2012). A Framework of a Web-Based Database System for National Health Insurance Scheme Asian Journal of Information Technology 11 (1): 7-13, 2012 ISS

[2] Agba, A. M., Ushie, E. M., and Osuchukwu, N. C. (2010) National Health Insurance Scheme (NHIS) and Employees' Access to Healthcare Services in Cross River State, Nigeria. Global Journal of Human Social Science 10(7): pp. 9-16

[3] Igodan E. C. and Ukaoha K. C. (2012). Toward a distributable database framework for the National Health Insurance Scheme. Journal of Mathematics and Technology Vol. $\quad 3(1)$ : pp 2078-0257.

[4] Lemon CA, Kim J, Haraguchi D, Sud A, Branley J, Khadra MH. (2013) Maintaining continuity of care in a multidisciplinary health service by using m-health technologies to develop patient medical records. Proceedings of the International Conference on Health Informatics (ICHI); 2013 Nov 7-9; Vilamoura, Portugal. p. 84-7.

[5] National Health Insurance Scheme Operational Guidelines (2012). Accessed on April 24, 2014 from
http://www.nhis.gov.ng/images/stories/hmoregister/NHI S.

[6] Obansa S. and Akinnagbe O. (2013). Health Care Financing in Nigeria: Prospects and Challenges. Mediterranean Journal of Social Sciences 4(1): pp. 224 225

[7] Odeyemi I. A. (2014). Community based HealthInsurance Programmes and the National Health Insurance Scheme of Nigeria: Challenges to Uptake and Integration. International Journal for Equity in Health. 13(20)

[8] Owusu- Sekyere E. and Bagah D. A. (2014). Towards a Sustainable Health Care Financing in Ghana: Is the National Health Insurance the Solution? Scientific \&Academic Publishing.Vol.4(5): pp. 185-194

[9] Oyegoke T., Ikono R., and Soriyan H. (2017).An Integrated Health Management System for National Health Insurance Scheme in Nigeria. Journal of Emerging Trends in Computing and Information Sciences, Vol. 8, No. 1 pp. $30-40$

[10] WorldHealthOrganization.(2011)mHealth: new horizons for health through mobile technologies. Geneva, Switzerland: World Health Organization; 2011

[11] World Health Organization (2012), "Development of an updated Action Plan for the Global Strategy for the prevention and Control of Noncommunicable Diseases covering the period 2013 to 2020 " Report.

[12] Idowu, A. P., Adeosun, O. O., \& Williams, K. O. (2014). Dependable online appointment booking system for NHIS outpatient in Nigeria teaching hospitals. International Journal of Computer Science \& Information Technology, 6(4), 59. 